\title{
Food consumption and nutritional status of people living with HIV/AIDS (PLWHA): a case of Thika and Bungoma Districts, Kenya
}

\author{
Elizabeth Nafula Kuria* \\ Department of Foods, Nutrition and Dietetics, Kenyatta University, PO Box 43844, Nairobi 00100, Kenya
}

Submitted 31 July 2008: Accepted 15 June 2009: First published online 17 September 2009

\begin{abstract}
Objective: To establish the food consumption, dietary habits and nutritional status of people living with HIV/AIDS (PLWHA) and adults whose HIV status is not established.

Design: Cross-sectional descriptive survey.

Setting: Thika and Bungoma Districts, Kenya.

Subjects: A random sample of 439 adults; 174 adults living with HIV/AIDS and

265 adults whose HIV/AIDS status was not established in Thika and Bungoma

Districts.

Results: Majority of PLWHA consume foods that are low in nutrients to build up the immune system and help maintain adequate weight, and there is little variety in the foods they consume. More adults who are HIV-positive are undernourished than those whose status is not established. Of the HIV-positive adults, those with a BMI of $\leq 18.5 \mathrm{~kg} / \mathrm{m}^{2}$ were $23.6 \%$ (Thika $20 \cdot 0 \%$ and Bungoma $25 \cdot 7 \%$ ) while of the adults whose status is not established those with $\mathrm{BMI} \leq 18.5 \mathrm{~kg} / \mathrm{m}^{2}$ were 13.9\% (Thika 9.3\% and Bungoma 16.7\%).

Conclusions: Adults who are HIV-positive are more likely to be undernourished than those whose status is not established, as there is a significant difference $(P=0 \cdot 000)$ between the nutritional status (BMI) of PLWHA and those whose HIV/ AIDS status is not established. PLWHA consume foods that are low in nutrients to promote their nutritional well-being and health.
\end{abstract}

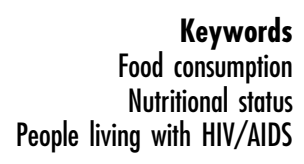

Keywords Nutritional status People living with HIV/AIDS
The HIV/AIDS pandemic has been on the rise in Kenya since the first case was reported in the country in 1984. The number of persons infected has increased up to $1 \cdot 3$ million $^{(1,2)}$. Majority of the caregivers of people living with HIV/AIDS (PLWHA) tend to be women and orphaned children. The orphaned children take care of their younger siblings and face hardships that are unique to their condition. Existing data suggest that nutrition interventions that increase energy and protein intakes may help build reserves and reduce the vulnerability of PLWHA to weight loss and wasting that accompanies other opportunistic infections ${ }^{(3,4)}$. In addition, appropriate nutrition ensures that the immune system is not heavily depleted ${ }^{(5)}$. Nutritional status of PLWHA in relation to persons whose HIV status is not known has received minimal attention.

Nutrition management of PLWHA has had a low profile in Kenya, where up to 700 people are reported to die daily from infections related to their HIV status. In order to contribute to improved quality of life of PLWHA, the present nutritional status and food consumption of
PLWHA was conceived. According to the Ministry of Health Annual Reports in Thika and Bungoma Districts, HIV/AIDS in the two districts is on the rise, weighing heavily on the bed capacities in the district hospitals (Ministry of Health, unpublished report).

The study sought to establish the food consumption, dietary habits and nutritional status of PLWHA, and adults whose HIV status is not established, in two districts in Kenya. Caregivers' knowledge on foods that improve the immune system and foods appropriate for nutritional wellbeing of HIV-positive persons is given minimal attention. The present study established nutrition knowledge of the caregivers.

\section{Material and methods}

A cross-sectional descriptive survey research was carried out in Bungoma and Thika Districts, Kenya, where HIV/ AIDS infection has been on the rise and there are many orphaned children taking care of other children. 
Training of team leaders and interviewers

Data were collected by persons, selected by the Ministry of Health, who were of secondary level of education and had experience in previous surveys. Training on the survey methodology, anthropometric measurements and data collection tools was conducted in a $3 \mathrm{~d}$ training workshop prior to the survey in each district.

\section{Pre-test}

On day 3 of the training, a half-day was allocated to pretesting by all the teams under supervision of the researcher and district nutritionist. The final questionnaires for the survey were finalized after reviewing the pre-test with the interviewers and team leaders.

\section{Selection of bousebolds}

Divisions were randomly selected in each district. Villages were subsequently randomly selected. In each village, the chief gave the number of households and from these, households were randomly selected to participate in the survey. Two interviewers went to each household whereby they explained the purpose of the study and sought consent to participate in the study. The member of the household responsible for food preparation and consumption was the one interviewed in each household. In households where there was a PLWHA, the PLWHA was interviewed along with his/her caregiver. Interview for each of the participants was held in their homes, where recording was done.

\section{Sample size}

A sample size of 439 participated in the study. This comprised of 174 adults living with HIV/AIDS and 265 adults whose HIV/AIDS status was not established.

\section{Data collection}

On this sample, an interview schedule was administered in February/March 2004 in Thika District and in May/ June 2004 in Bungoma District to establish the sociodemographic characteristics and nutrition care practices. The food consumption was established using a $24 \mathrm{~h}$ recall and weekly food frequency. Anthropometric measurements were taken and calculated to establish the nutritional status of the sample. Focus groups were held for key informants from the two districts in September/ October 2004. Quantitative data from the interviews were analysed using the SPSS statistical software package (SPSS Inc., Chicago, IL, USA). The EPI-INFO program (Centers for Disease Control and Prevention, Atlanta, GA, USA) was used to establish the nutritional status of the study sample. BMI was calculated for adults.

\section{Data quality control}

Procedures to ensure quality data included: careful training of interviewers, close supervision of actual survey and daily check of all the questionnaires for consistency, completeness and clarity by the researcher. Questionnaires obtained at the end of each day were checked. Any errors or omissions in data recording were sorted and if any information was missing, the particular household was revisited to get complete information the following day.

\section{Limitation of the study}

The nutrient contents of the foods consumed were not analysed as this was to be done during the second phase of the project.

\section{Results and discussion}

\section{Nutrition care of people living with HIV/AIDS}

Of the 174 adults, $81 \%$ had caregivers while $19 \%$ took care of themselves. It should be observed that PLWHA were at different stages of HIV/AIDS progression. Majority of the caregivers, $90 \%$, stated that nutrition is important for PLWHA. However only a few of them, 5\%, could indicate what proper nutrition meant. A written handout on nutrition care developed by the researcher was explained and given to PLWHA for their use after each interview.

Food consumption by people living with HIV/AIDS Caregivers and PLWHA, as appropriate, were asked to indicate the foods that PLWHA consume. Table 1 shows

Table 1 Foods consumed by people living with HIV/AIDS $24 \mathrm{~h}$ prior to the interview in Thika and Bungoma Districts

\begin{tabular}{|c|c|c|c|}
\hline Foods & $\begin{array}{l}\text { Thika } \\
(n)\end{array}$ & $\begin{array}{l}\text { Bungoma } \\
(n)\end{array}$ & $\begin{array}{c}\text { Total } \\
(n \text { 177) }\end{array}$ \\
\hline \multicolumn{4}{|l|}{ Cereals based/staples } \\
\hline Ugali & 28 & 76 & 104 \\
\hline Rice & 28 & 21 & 49 \\
\hline Porridge (Uji) & 16 & 14 & 30 \\
\hline Githeri (maize and beans) & 6 & 11 & 17 \\
\hline Green maize & 0 & 7 & 7 \\
\hline Mandazi & 1 & 4 & 5 \\
\hline Bread & 2 & 2 & 4 \\
\hline Chapatti & 1 & 2 & 3 \\
\hline Sorghum & 3 & 0 & 3 \\
\hline Cake & 1 & 1 & 2 \\
\hline Millet ugali & 0 & 2 & 2 \\
\hline \multicolumn{4}{|l|}{ Roots and tubers } \\
\hline Irish potatoes & 9 & 14 & 23 \\
\hline Sweet potatoes & 1 & 11 & 12 \\
\hline Cassava & 0 & 3 & 3 \\
\hline Arrow roots & 2 & 0 & 2 \\
\hline \multicolumn{4}{|l|}{ Fruits } \\
\hline Fruits & 15 & 8 & 23 \\
\hline \multicolumn{4}{|l|}{ Vegetables } \\
\hline Vegetables & 29 & 50 & 79 \\
\hline \multicolumn{4}{|l|}{ Meats/animal products } \\
\hline Milk & 15 & 11 & 26 \\
\hline Eggs & 11 & 6 & 17 \\
\hline Meat stew & 7 & 9 & 16 \\
\hline Fish stew & 4 & 7 & 11 \\
\hline \multicolumn{4}{|l|}{ Legumes/pulses } \\
\hline Bean stew & 23 & 19 & 42 \\
\hline Pulse stew & 8 & 0 & 8 \\
\hline Soyabeans & 0 & 1 & 1 \\
\hline Others (sodas, tea) & 5 & 25 & 30 \\
\hline
\end{tabular}


the foods that were fed to PLWHA. Majority of PLWHA persons consume foods that are low in nutrients to build up the immune system, help maintain adequate weight and there is little variety of foods consumed. From the findings, it is observed that foods that are rich in vitamins $\mathrm{A}$ and $\mathrm{C}$, such as fruits and dark green vegetables; those rich in zinc, such as seeds of pumpkins, water melons; and foods rich in fats, such as groundnuts and avocados that increase energy density of foods, are rarely given to PLWHA on a regular basis. Meats and legumes, important for bodybuilding, are consumed by less than a quarter of the sampled households. This suggests a lack of knowledge on foods appropriate for PLWHA that is of concern and needs to be addressed. Since this study, NASCOP (National AIDS/STDs Control Programme) has developed nutrition care materials for PLWHA, for service providers ${ }^{(6,7)}$. There are still limited materials accessible to the PLWHA themselves.

\section{Perceptions by caregivers of foods that deplete and enbance the immune system}

For PLWHA, consuming foods that enhance their immunity is vital to slow down progression of HIV to full blown AIDS and for effective utilization of the anti-retroviral medication $^{(5)}$. The PLWHA and their caregivers were asked to indicate the foods that build up the immune system and those that deplete the immune system. The responses given were varied and only a very small proportion, $6 \%$, of the respondents indicated appropriate foods that are associated with building or depleting the immune system. Table 1 gives the foods consumed by PLWHA a day before the survey was undertaken.

Reasons for giving the different foods to PLWHA included: to enhance immunity, provide energy, patients' preference, for bodybuilding, to maintain good health, availability of food and ease of digestibility of food. However, when asked foods that build the immune system, the responses given were not appropriate for most of the respondents.

These results indicate that PLWHA and their caregivers have minimal knowledge on foods that either improve or deplete the immune system. This is in agreement with early research in Thika, where it was found that community health workers who communicate nutrition and health messages to people in the community had received minimal training in nutrition and HIV/AIDS ${ }^{(8)}$. In some cases, foods that have been noted to deplete the immune system, such as sugar, were wrongly indicated as improving the immune system. For example, $29 \%$ ( $n$ 57) of the caregivers and PLWHA inappropriately stated that cakes/sugar improves the immune system of PLWHA. This is contrary to various documentations that indicate that table sugar actually depletes the immune system although it increases energy intake ${ }^{(9)}$. The caregivers did not indicate vegetables and fruits as contributing to enhance the immune system. This calls for nutrition education and counselling on foods that enhance the immunity that can be promoted for consumption. On the other hand, PLWHA should be discouraged from consuming foods that depress the immune system so that they maintain a healthy immune system.

\section{Nutritional status}

Nutritional status of PLWHA and those whose status was not known was established. Malnutrition places PLWHA at an increased risk of getting opportunistic infections ${ }^{(3,5)}$. Data on weight and height of adults was collected to establish the nutritional status of adults. These data were used to derive the BMI. The BMI is used to measure thinness or obesity. A cut-off point of $18.5 \mathrm{~kg} / \mathrm{m}^{2}$ defines (thinness) acute under-nutrition. A BMI of $25 \mathrm{~kg} / \mathrm{m}^{2}$ and above usually indicates overweight or obesity. Table 2 shows the BMI of adults in the study.

The mean BMI at the national level is $23 \mathrm{~kg} / \mathrm{m}^{2}$ according to the Kenya Demographic Health Survey ${ }^{(10)}$. In both districts, the proportion of adults who were thin/underweight is higher among the PLWHA (Thika $20.0 \%$ and Bungoma $25.7 \%)$ than in those whose status is not established (Thika $9 \cdot 3 \%$ and Bungoma 16.7\%). As expected, the PLWHA are at a higher malnutrition risk. This is in line with other literature that suggests that PLWHA are at high malnutrition risk ${ }^{(11)}$.

In the two districts, the PLWHA were more underweight than those whose HIV status was not established. In Thika District, PLWHA with BMI $<18.5 \mathrm{~kg} / \mathrm{m}^{2}$ were $17 \cdot 2 \%$ compared to $11 \cdot 2 \%$ of those whose status was not known. On the other hand, in Bungoma District $25.7 \%$ of the PLWHA respondents had a BMI $<18.5 \mathrm{~kg} / \mathrm{m}^{2}$ as compared to $16.0 \%$ of those whose status was not established. Among the adults, there was a significant difference $(P=0 \cdot 000)$ between the nutritional status (BMI) of PLWHA and those whose status was not established. This suggests that PLWHA are at a higher nutrition risk and strategies should be targeted to improve their nutrition. Nutritional wellbeing for HIV-positive persons should lay an emphasis on avoiding wasting ${ }^{(12)}$. A focus to enable HIV-positive persons not to be wasted will lead to improved nutritional well-being.

In Thika District, PLWHA with BMI $\geq 25 \cdot 0 \mathrm{~kg} / \mathrm{m}^{2}$ were $12 \cdot 0 \%$ compared to $28.6 \%$ of those whose status was not known. On the other hand, in Bungoma District, $8.5 \%$ of the PLWHA had a BMI $\geq 25 \cdot 0 \mathrm{~kg} / \mathrm{m}^{2}$ as compared to $22 \cdot 0 \%$ of those whose status was not established. This indicates that overweight is also an area of nutrition concern for the adult population in general in the two districts. It may be noted that overweight is culturally perceived to indicate wealth among most of the rural communities in Kenya.

Analysis of under-nutrition for adults, by gender, showed that in Thika more males, $28.8 \%$, were underweight compared to $10 \cdot 1 \%$ of the females, whereas in Bungoma more females, $24 \cdot 4 \%$, were underweight compared to $11 \cdot 8 \%$ of the males. In addressing under-nutrition of adults in the two 
Table 2 Nutritional status (BMI) of adults by categories and background characteristics in Thika and Bungoma Districts

\begin{tabular}{|c|c|c|c|c|}
\hline \multirow[b]{2}{*}{ Characteristics } & \multicolumn{4}{|c|}{ BMI $\left(\mathrm{kg} / \mathrm{m}^{2}\right)$} \\
\hline & Thin $(<18 \cdot 5)$ & Normal $(18 \cdot 6-25 \cdot 9)$ & Overweight $(\geq 25 \cdot 0)$ & Number of adults \\
\hline \multicolumn{5}{|l|}{ Thika } \\
\hline \multicolumn{5}{|l|}{ Age in years } \\
\hline $15-19$ & $29 \cdot 0$ & $71 \cdot 0$ & 0 & 31 \\
\hline $20-24$ & $13 \cdot 3$ & $66 \cdot 7$ & $20 \cdot 0$ & 30 \\
\hline $25-29$ & $9 \cdot 1$ & $68 \cdot 2$ & $22 \cdot 7$ & 22 \\
\hline 30-34 & $12 \cdot 5$ & $59 \cdot 4$ & $28 \cdot 2$ & 32 \\
\hline $35-39$ & $15 \cdot 0$ & $60 \cdot 0$ & $25 \cdot 0$ & 20 \\
\hline $40-44$ & $23 \cdot 8$ & $71 \cdot 4$ & $4 \cdot 8$ & 21 \\
\hline $44-49$ & $30 \cdot 0$ & $50 \cdot 0$ & $20 \cdot 0$ & 10 \\
\hline$>50$ & $6 \cdot 8$ & $51 \cdot 7$ & $41 \cdot 3$ & 29 \\
\hline \multicolumn{5}{|l|}{ Sex } \\
\hline Male & $28 \cdot 8$ & $57 \cdot 6$ & $13 \cdot 6$ & 66 \\
\hline Female & $10 \cdot 1$ & $65 \cdot 9$ & $24 \cdot 1$ & 129 \\
\hline \multicolumn{5}{|l|}{ Education } \\
\hline None & $21 \cdot 4$ & $71 \cdot 4$ & $7 \cdot 1$ & 14 \\
\hline Primary & $23 \cdot 4$ & $55 \cdot 3$ & $20 \cdot 3$ & 94 \\
\hline Secondary & $9 \cdot 5$ & $71 \cdot 6$ & $18 \cdot 9$ & 74 \\
\hline Post secondary & 0 & $61 \cdot 5$ & $38 \cdot 5$ & 13 \\
\hline \multicolumn{5}{|l|}{ Category } \\
\hline PLWHA & $17 \cdot 2$ & $70 \cdot 6$ & $12 \cdot 0$ & 69 \\
\hline HIV status not established & $11 \cdot 3$ & $60 \cdot 0$ & $28 \cdot 6$ & 126 \\
\hline \multicolumn{5}{|l|}{ Bungoma } \\
\hline \multicolumn{5}{|l|}{ Age in years } \\
\hline $15-19$ & $18 \cdot 8$ & $64 \cdot 6$ & $16 \cdot 6$ & 48 \\
\hline $20-24$ & $19 \cdot 0$ & $76 \cdot 2$ & $4 \cdot 8$ & 21 \\
\hline $25-29$ & $31 \cdot 0$ & $51 \cdot 7$ & $27 \cdot 2$ & 29 \\
\hline $30-34$ & $12 \cdot 5$ & $79 \cdot 2$ & $8 \cdot 3$ & 24 \\
\hline $35-39$ & $22 \cdot 2$ & $66 \cdot 7$ & $11 \cdot 1$ & 27 \\
\hline $40-44$ & $24 \cdot 2$ & $54 \cdot 7$ & $21 \cdot 2$ & 33 \\
\hline $44-49$ & $8 \cdot 0$ & $72 \cdot 0$ & $20 \cdot 0$ & 25 \\
\hline$>50$ & $24 \cdot 3$ & $62 \cdot 1$ & $13 \cdot 5$ & 37 \\
\hline \multicolumn{5}{|l|}{ Sex } \\
\hline Male & $11 \cdot 8$ & $73 \cdot 7$ & $14 \cdot 5$ & 76 \\
\hline Female & $24 \cdot 4$ & $60 \cdot 7$ & $14 \cdot 8$ & 168 \\
\hline \multicolumn{5}{|l|}{ Education } \\
\hline None & $4 \cdot 3$ & $73 \cdot 9$ & $21 \cdot 7$ & 23 \\
\hline Primary & $22 \cdot 6$ & $66 \cdot 5$ & $11 \cdot 0$ & 155 \\
\hline Secondary & $19 \cdot 0$ & $62 \cdot 1$ & $19 \cdot 0$ & 58 \\
\hline Post secondary & $20 \cdot 5$ & $25 \cdot 0$ & $37 \cdot 5$ & 8 \\
\hline \multicolumn{5}{|l|}{ Category } \\
\hline PLWHA & $25 \cdot 7$ & $65 \cdot 7$ & 8.5 & 105 \\
\hline HIV status not established & $16 \cdot 0$ & $62 \cdot 0$ & $22 \cdot 0$ & 139 \\
\hline
\end{tabular}

PLWHA, people living with HIV/AIDS.

districts, gender access to food and health care should be investigated.

Of the respondents in Thika District, those with no education, $21 \cdot 4 \%$, and those with primary level of education, $23 \cdot 4 \%$, were the majority of the ones who were underweight with a $\mathrm{BMI}<18.5 \mathrm{~kg} / \mathrm{m}^{2}$. However, in Bungoma District, proportions of those with high rates of underweight were adults with primary education, $22 \cdot 6 \%$, followed by post secondary education, $20 \cdot 5 \%$, and secondary level of education, $19 \cdot 0 \%$. These results imply that in Thika District, those with lower levels of education are more likely to be undernourished than those with high levels of education. This is not the case in Bungoma. It is apparent that those with high levels of education still experience under-nutrition in Bungoma. This could be due to the few economic activities in the district that limit opportunities for gainful employment. There was however a positive but weak positive correlation $(r=0 \cdot 245)$ which was significant $(P=0 \cdot 00)$ between the education level of adults and the BMI, at 0.05 level of significance. This suggests that education is important for improvement of nutritional well-being.

In Thika District, the age bracket with the highest rate of underweight was those aged over 40 years, where $60 \cdot 6 \%$ had a BMI $<18 \cdot 5 \mathrm{~kg} / \mathrm{m}^{2}$. A similar scenario could be stated for $56.6 \%$ of the adults in Bungoma above 40 years. This may suggest that the nutritional well-being of all adults needs attention even as they grow older.

From the findings, it is essential that nutrition for adults needs attention to avoid wasting. Of major concern is the fact that PLWHA should be targeted to avoid wasting. This, among others, can be achieved by increasing the use of locally accessible energy- and nutrient-dense foods such as groundnuts and avocados. These were widely available in 
the two districts during this research but were minimally consumed based on the $24 \mathrm{~h}$ recall and the food frequency. Development of available, easy-to-prepare and easy-to-use foods should be promoted for the PLWHA due to their increased energy needs.

\section{Conclusion/recommendations}

People living with HIV and AIDS and their caregivers have minimal knowledge on foods that are appropriate for their health and nutritional well-being. Adults who are HIVpositive are more likely to be undernourished than those whose status is not established, as there is a significant difference $(P=0 \cdot 000)$ between the nutritional status (BMI) of PLWHA and those whose HIV/AIDS status is not established. Strategies to improve the nutritional status of PLWHA require to be prioritized in the care of PLWHA with a focus on foods that are available and on food preparation.

Nutrition education and counselling that is practical at the community level needs to be focused upon for improving the well-being of PLWHA. Attention to gender access to food, and health care and nutrition of the elderly, should be investigated when addressing food and nutrition security of HIV and AIDS persons. Nutritional well-being for the adult population needs to be addressed; as indicated in the present study, $40 \%$ of adults whose HIV status was not established were malnourished (11\% undernourished; 29\% overweight) in Thika District and 38\% in Bungoma District (16\% undernourished; $22 \%$ overweight).

\section{Acknowledgements}

This research was made possible with financial support from Nutrition Third World and logistical support from Kenyatta University. The Ministry of Health in Thika and Bungoma Districts played a key role during the data collection and research dissemination process. I am grateful to these institutions because of which the undertaking of the present study was made possible. There are no conflict of interests to declare.

\section{References}

1. Ministry of Health (2001) AIDS in Kenya: Background, Projections, Impact, Interventions and Policy. Nairobi: Ministry of Health.

2. National AIDS/STDs Control Programme (1999) AIDS in Kenya. Background Projects, Impact and Intervention Policies. Nairobi: NASCOP.

3. National AIDS Programme (2001) A Healthy Diet for Better Nutrition for People Living with HIV/AIDS. Nairobi: NAP.

4. World Health Organization (2003) Nutrient Requirements for People Living with HIV/AIDS. Geneva: WHO.

5. National AIDS/STDs Control Programme, Food and Nutrition Technical Assistance and UNICEF (2007) Kenya Guidelines on Nutrition and HIV/AIDS. Nairobi: NASCOP.

6. National AIDS/STDs Control Programme/Food and Nutrition Technical Assistance (2007) HIV Nutrition Management in Comprehensive Care Centres in Kenya: A Trainer's Manual and Nutrition and HIV/AIDS: A Toolkit for Service Providers in the Comprehensive Care Centres. Nairobi: NASCOP/FANTA.

7. Food and Agriculture Organization of the United Nations/ World Health Organization (2002) Living Well with HIV/ AIDS: A Manual on Nutrition Care and Support for People Living with HIV/AIDS. Rome: FAO.

8. Kuria EN (2000) Participation and the focus of nutrition education in a rural child growth monitoring program in Kenya. PhD Thesis, Edith Cowan University, Western Australia.

9. Saputo L \& Faass N (2003) Boosting Immunity: Creating Wellness Naturally. Mumbai: Magna Publications Co. Ltd.

10. Central Bureau of Statistics (2003) Kenya Demographic Health Survey. Nairobi: The Government Printer.

11. Piwoz E \& Preble E (2000) HIV/AIDS and Nutrition. A Review of the Literature and Recommendations for the Nutritional Care and Support in Sub-Saharan Africa. Washington: SARA.

12. Food and Nutrition Technical Assistance (2001) HIV/AIDS: A Guide for Nutrition, Care and Support. Washington, DC: FANTA. 